\title{
Community non-participation in homestays in Kullu, Himachal Pradesh, India
}

Jyoti Sood ${ }^{\mathrm{a}, 1}$, Paul Lynch ${ }^{\mathrm{b}}$, Constantia Anastasiadou ${ }^{\mathrm{b}}$

${ }^{a}$ Institute of Vocational Studies, Himachal Pradesh University, Himachal Pradesh, India-171005

${ }^{b}$ School of Marketing, Tourism \& Languages, Edinburgh Napier University, Edinburgh EH14

1DJ

${ }^{1}$ Corresponding author, Tel: +1 (972) 863-2040,

Email: jyotisoodmta@gmail.com 


\begin{abstract}
An upsurge in popularity of homestays has provided newer economic opportunities to remote Indian Himalayan communities. Despite the benefits homestays offer, their acceptance by mountain communities is fraught with challenges. This qualitative research study has listened to and given voice to homestay scheme non-participants, community members from 15 villages in the Kullu region. Through thematic analysis, rational, understandable reasons leading to decisions not to engage are identified: socio-cultural; practical and apprehensions. Reasons include an inability to comply with certain guidelines of the scheme, inadequacy in sanitary infrastructure, gender roles, complex socio-cultural issues and also home model issues, which all condition the scheme implementation. The concept of 'deliberate non-participation' is advanced which extends previous typologies of community participation. Further theoretical and practical implications of the study are discussed along with recommendations for future development of the homestay scheme.
\end{abstract}

Key words: Homestay, Himalayas, socio-cultural sensibilities, constraints, community nonparticipation 


\section{Community non-participation in homestays in Kullu, Himachal Pradesh, India}

\section{Introduction}

Mountainous and remote rural regions in developing countries, typically characterised by subsistence economies, high levels of poverty and fragile natural environments, face distinctive challenges in tourism development. Since mountain communities in Asia overtly rely on agriculture and pastoralism and are vulnerable to climate change and other calamities (Vedwan, 2006), it is important they diversify to other non-farm livelihoods (Rasul \& Kollmair, 2010). Tourism is an option but environmental, economic and socio-political factors may influence the degree of participation in tourism by mountain communities (Nyaupane, Morais, \& Dowler, 2006). Policymakers' failure to understand the geographic and social uniqueness of mountainous regions and to involve their communities, often leave efforts to create sustainable tourism products ineffective (Nepal \& Chipeniuk, 2005). Tourism development in the Himalayas presents a paradox to planners as they must balance 'developmental' and 'ecological' considerations. Case studies in the Himalayas have shown that (mass) tourism, initially touted as a means of economic and infrastructural development has ultimately incurred negative consequences for their ecology and culture (Cole, 2000)). Recently, rural tourism and homestays have emerged as a solution to this unregulated tourism development dilemma in developing countries and India, gaining popularity among tourists as well as host communities (Mura, 2015).

Homestays may help supplement the modest incomes of the hosts, generally from rural agrarian economies (Dahles, 2000; Liu, 2006) and could be more beneficial to indigenous economies than the creation of large hotels owned by outsiders (Andriotis, 2002). According to 
MoT India/UNDP (Ministry of Tourism (MoT) India/United Nations Development Programme) (2008) homestays are a central part of the tourism product offering in most of the rural tourism projects in India. Policymakers are vigorously promoting homestays to address the increasing tourist accommodation deficit (ibid) and to stimulate the rural economy. However, creating suitable accommodation models to promote sustainable tourism poses specific challenges, as this paper explores in a case from the Himalayan region of India.

Rather than the local communities, private organisations located in urban settings control the traditional commercial tourism widely practised in the Himalayan region (Campbell, 2008) and problems associated with negative impacts of tourism, resource ownership and use are evident. Many mountain destinations are facing problems of unplanned and indiscreet expansionism as, for example, with hotel developments in Manali (Cole, 2000). In contrast, in the Himalayan states of Uttarakhand (Bhalla, Coghlan \& Bhattacharya, 2016), Sikkim (Peaty, 2010), and Ladakh region of Jammu and Kashmir (Anand, Chandan, \& Singh, 2012), homestays have emerged as a sustainable accommodation option and have helped in generating livelihoods and supplementary incomes for the local people. Appraised in terms of an increased tourist visitation and community development, their success is attributed to two main factors: firstly, the engagement and involvement of local people from the decision-making stage to implementation of these community-based initiatives, and secondly, the leadership of a local non-governmental organisation (NGO) which spearheads these initiatives and provides financial, training and marketing support. Such positive initiatives are limited though and need appraisal over a longer period to evaluate their success. Hence, MoT India/UNDP (2008) advises policymakers in India "to approach aspects of positioning vis-à-vis local cultures more cautiously, as the risks, levels of comfort and willingness of the communities to embrace this option must be studied with a sense 
of openness and objectivity” (p.9). For example, Lama and Sattar (2002) observe that culture may affect a household's ability to participate in homestays, as some mountain communities have limitations on eating with or letting people of other religions or ethnicity stay in their houses.

While homestays are deemed to benefit communities, their acceptance by the community is often fraught with many challenges so it is important to understand the reasons that affect involvement. Accordingly, this paper explores the reasons why a rural community is not participating in the homestay scheme. The main objectives of this study are to: a) study the awareness of the host community about homestays and the HP Homestay scheme; and b) identify the challenges faced by members of the community in starting a homestay venture. The paper reviews literature relevant to homestays, focusing upon the challenges associated with community engagement before introducing the study area, the Kullu district of India's Himalayas, and its tourist accommodation development; next follows a description of the research methods and presentation of the study findings and then, the discussion and conclusion. In this paper, we employ literature on homestays, under the umbrella of commercial home enterprises, as a vehicle to explore community non-participation in (homestay) tourism. Commercial home enterprises, which embrace homestays, are:

"types of accommodation where tourists or guests pay to stay in private homes, where interaction takes place with a host and/or family usually living upon the premises, and with whom public space is, to a degree, shared” (Lynch 2005, p.528).

Our situation-specific definition of community based tourism (CBT) is tourism in which local residents (often rural, poor and economically marginalised) facilitate tourists visiting their communities with the provision of overnight accommodation like homestays. Our definition of 
'community non-participation' in the specific context of this paper refers to long-term residents of the site under study who do not engage in running homestays.

\section{Community Participation \& Homestays}

Homestays are a cross-disciplinary research topic and the available literature reflects the diversity of perspectives as well as diversity in research quality. The paper predominantly draws upon academic studies but on occasion, owing to the value that they bring, makes use of postgraduate dissertations, as well as NGO project development reports concerned with: mountain research and development, geography, ecology, sustainability, poverty reduction, gender and entrepreneurship.

Governments of many developing countries are actively promoting homestays as these provide additional income, employment (Chipumuro \& Lynette, 2011; Razzaq et al., 2011) and assist in distributing the benefits of tourism to rural areas (Beliveau, Castagna, Cicchetti, \& Jacques, 2012; Pusiran \& Xiao, 2013). However, host communities may not be able to take advantage of the benefits of homestays and certain sections of the community may get benefits over others (Mura, 2015). Often rural communities and development planners hold divergent views, which lead to the failure of the tourism development plans (Chalip \& Costa, 2012; Cole, 2000). Consequently, community participation in tourism development becomes a theoretical rather than practical concept (Tosun, 2002). Further, the centralised structure of planning (Nyaupane et al., 2006; Tosun, 2000) results in an overly bureaucratic role in decision-making and community non-involvement.

Scholars have argued the significance of community involvement in the successful development of tourism (Scheyvens, 1999; Tosun, 2000), and stressed the need to identify 
participation constraints perceived by a community (Cole, 2006; Tosun, 2002). Stone (as cited in Tosun, 2000, p.615) contends that community participation necessitates the design of 'development in such a way that intended beneficiaries are encouraged to take matters into their own hands, to participate in their own development through mobilising their own resources, defining their own needs, and making their own decisions about how to meet them'.

Figure 1 summarises the three major typologies on levels of community participation (after Arnstein, 1969; Pretty, 1995; Tosun, 1999). In all these typologies, at one end of the spectrum is non-participation by the community and at the other is participation, with various levels of engagement in between. The highest form of participation, 'spontaneous participation' in Tosun's typology corresponds to 'degrees of citizen power' in Arnstein's typology; and to 'selfmobilisation' and 'interactive' participation in Pretty's model. It represents maximum community control, power and awareness and is a non-centralised bottom-up approach. Conversely, there is ‘Coercive participation’ in Tosun’s typology, which tallies with Arnstein’s non-participation and Pretty's 'passive' and 'manipulative' participation. Coercive participation refers to a centralised top-down approach, mostly observed in developing countries, where maximum control is external and participants are mostly unaware and do not have any decision making roles in planning.

While the above typologies were focused on a range of levels of community participation, Hung, Sirakaya-Turk and Ingram (2011) and Kayat (2002) combined the factors that influenced participation (means) with the different level of participation (ends) into single frameworks. 
7. Selfmobilisation 6. Interactive participation
8. Citizen Control

7. Delegated power

6. Partnership

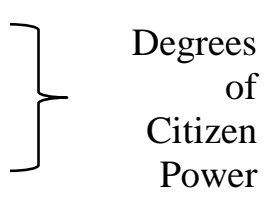

Spontaneous Participation:

Bottom-up, authentic, active/direct participation, participation in decision making.

5. Functional participation 4. Participation for material incentives 3. Participation by

5. Placation

4. Consultation

3. Informing consultation

2. Passive participation 1. Manipulative participation
2. Therapy

1. Manipulation

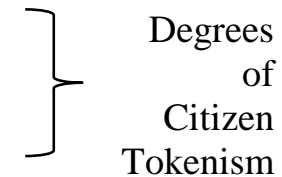

Induced Participation:

Top-down, passive, mostly indirect, pseudo participation.

Figure 1. Typologies of Levels of Community Participation. Adapted from "Expected Nature of

Community Participation in Tourism Development,” by C. Tosun, 2006, Tourism Management, 27, p.494.

Based on Pretty’s typology, Kayat (2002) proposed a framework which suggests three critical factors affecting community participation: motivating factors; control in decisionmaking; and ability to take advantage of economic opportunities that arise due to tourism development. Motivation is a major factor that influences participation. 'Motivation' itself is influenced by factors such as awareness about benefits of tourism, social /affiliation needs and the personality traits of people in the community. Fair access and equitability affect an individual's 'control in decision-making', that is, power to get involved in goal formulation, strategy development, implementation and monitoring. Lastly, participation can also be affected by an individual's 'ability'; ability is greater when individuals have better access to information and capital. In Kayat's (2002) study, while community members had a similar ability to engage in homestays since it was a co-operative programme and did not require significant capital to start and modest housing sufficed, it was mostly 'motivation' that influenced a community 
member's decision to become a host or not. On similar lines, Hung et al. (2011) proposed the 'Motivation-Opportunity-Ability (MOA) Model', which identified three factors that influence community participation. First, perceived benefits that 'motivate' or drive communities towards participation; second, presence of enabling 'opportunities', e.g., decentralisation of power structures can provide greater control in decision making to community members; and third, 'ability’ which is a combination of awareness, experience, skills and accessibility to information and resources.

Tosun (2000) observed that community involvement in the tourism development process may be considered either in the decision-making process or in the benefits from tourism development. He identified operational, structural and cultural factors; which limit the practical participation of communities in the 'decision-making' process of tourism development. Some of the stated limitations include regional power structures, a centralisation of power, domination of elites, low awareness and a lack of knowledge about tourism. According to him, these limitations may be a reflection of the prevailing social, cultural and economic structures of developing countries and thus, without bringing change into their socio-economic and political structures, community participation cannot become a reality. Nyaupane et al. (2006) also identified certain limitations to community participation, namely: lack of capital; cultural limitations; tourism as a concept may be alien to the community; and centralised political structures leading to overreliance on government for initiative and decisions.

In agricultural societies, the transition to tourism or hospitality may be a difficult choice because of: a) the lack of entrepreneurial steering and an over-reliance of communities on the Government (Chipumuro \& Lynette, 2011); b) lack of enthusiasm among residents due to their unfamiliarity with the nature of tourism (Liu, 2006); c) a need for a change of attitude to offer 
services as a way of living (Reichel, Lowengart, \& Milman, 2000); d) lack of skills and training opportunities in hospitality and tourism (Sharpley \& Vass, 2006; Tosun, 2000); e) the difficulties that isolated communities may experience in interfacing with new cultures (Sharpley \& Vass, 2006); and f) a fear of facing jealousy and ostracism by their own community members (Tucker, 2010). Tucker (2010) discussed the subversive attitude of peasant societies in Turkish villages towards tourism entrepreneurship. Similarly, Acharya and Halpenny (2014, p. 379) observed that in the Barapak village, Nepal, women whose households are not yet permitted as homestays are prejudiced against the ones who are operating them. A negative attitude and disunity among the community may threaten the sustainability of the homestay programme as a tourism development strategy (Pusiran \& Xiao, 2013).

A very limited amount of work on homestays as a community-based tourism product and associated challenges has been conducted so far. In South Africa, Chipumuro and Lynette (2011) and Kwaramba, Lovett, Louw, \& Chipumuro (2012) highlighted the challenges faced by women homestay operators in the Kwam eMakana homestay initiative. The major challenges identified in both studies were low awareness of product, lack of direction of the homestay project; low motivation for growth; diminished networking capabilities; and dependence on government for the promotion of homestays. Kwaramba et al. (2012) observe that due to the long history of apartheid, women homestay entrepreneurs faced challenges of low Emotional Intelligence (selfconfidence, self and social awareness and social skills) and failed to capitalise on opportunities for economic advancement.

In Malaysia, Kayat’s (2002) study of a Homestay programme revealed that in spite of having motivation, ability and opportunity, personal reasons such as size of house, family issues and time constraints influenced some community members' readiness to participate. Otherwise, 
everybody who was willing could participate, as there was no requirement of significant start-up capital or skills to get into the programme. Further, two studies by Pusiran and Xiao (2013), and Nor Ashikin and Kayat (2010), show that community-run homestay programmes are vulnerable to internal and external challenges. Pusiran and Xiao (2013) reported external challenges like incompetent leadership, inefficient networking and misuse of the term 'homestay' by irresponsible external parties who exploit the name for their own benefit. Internal challenges included lack of knowledge of the tourism industry; lack of entrepreneurial skills; overdependence on Government; and a lack of commitment towards the homestay programme by the next generation thereby affecting long-term sustainability. Nor Ashikin and Kayat (2010) also identified that there was a misconception of homestays among new hosts and their inspection committee, which meant poorer householders could not register. For registering the homestay the hosts had to attend a training programme and after that get their house endorsed by an inspection committee. However, what was advised in training was very different from the actual amenities being sought by the inspection team. Hence, by failing to comply with hotel-like standards, poor households could not register. Other problems included: delayed payments; lack of leadership; migration of youth to cities; passive nature of the community which overly depended on the Government for future development of homestays; leadership problems; informal structure and management issues of the homestay association; over-commercialisation that ended up benefitting a few; and conflict among community members.

Beliveau et al.'s (2012) study of homestays in Namibia suggested that hosts expect guests to be conscious of cultural clashes, respect household rules (on issues like smoking, consumption of alcohol and curfew timings) and adhere to health and safety precautions. Kontogeorgopoulos, Churyen, and Duangsaeng (2015) observed that the success of homestays in Thailand has 
brought in multiple challenges and perceived threats among operators such as fear of loss of: rural authenticity; social harmony; economic diversification (as homestays have led to increased reliance on tourism).

All the above typologies and frameworks address non-participation only indirectly and in a limited sense. The MOA model of Hung et al. (2011) explores three antecedents/factors (motivation, opportunity, ability) which can affect the level of participation but we have limited understanding of the nature of the factors that can affect motivation, opportunity, and ability. The studies on homestays have surfaced fragmented aspects of individual challenges associated with active homestay hosts and have looked into challenges that communities face after they participate in homestays or community based homestay programmes. However, we hold the view that there is an alternative way of considering community involvement, that is, from seeking to understand community non-involvement in specific tourism development policies. Such an approach, we feel deepens our understanding by giving primacy to the arguably silenced voices of community members.

\subsection{Homestays in Indian Himalayas}

Despite the challenges involved in developing homestays, the Himalayan Homestays in Sikkim, Ladakh and Spiti have been identified as a useful tool in preserving the rapidly deteriorating Himalayan natural and cultural resources; empowering women and providing sustainable livelihoods to the local communities (Anand et al., 2012; Lama, Jackson, \& Wangchuk, 2012).

The Ladakh Himalayan Homestay programme is considered as one of the best examples of community inclusion and ownership in tourism (MoT India/UNDP, 2008). The Himalayan 
Homestays in Ladakh, initiated by the Snow Leopard Conservancy in association with local community and funding from UNESCO, have supplemented income of households, helped preserve threatened wildlife and increased ownership by local people in the initiative (Lama et al., 2012). Peaty (2010) analysed four different projects on community-based homestay tourism in the Indian Himalayas and found that in spite of different approaches, all the projects provided significant monetary and non-monetary benefits to the community, assisted in protection and preservation of environment and culture; and enabled youth and female empowerment.

Anand et al.’s (2012) study concluded that despite the characteristic challenges faced by many mountain regions such as inadequate skills, meagre income-generating opportunities, the Korzok Project in Ladakh, was beneficial in integrating environmental conservation goals with community development needs, with women playing an integral role in its success. In the Barapaki region of rural Nepal, homestays helped address many socio-economic, political and gender disparities (Acharya and Halpenny, 2014). The involvement of women in homestays has helped address gender inequalities and long held beliefs on the conventional gender role of women as homemakers.

Studies on Himalayan homestays in India have mainly reported on the success of community-based homestay initiatives in Ladakh, Spiti and Sikkim but have largely ignored the challenges that communities face before they decide to participate in the homestay movement. Since no previous research exists that identifies reasons for community non-participation in the Indian Himalayas, it was appropriate to undertake an exploratory study. 


\subsection{The Development of Tourism and Homestays in Kullu}

According to Census of India (2011), Himachal Pradesh (HP) is a Himalayan state with the highest percentage of rural population in India (89.95\%). The Kullu district of HP is situated in the Pir Panjal range of Western Himalayas (Figure 2) and divided into six major blocks: Kullu, Manali, Sainj, Banjar, Nermand and Ani. Kullu attracts tourists from all over the world due to its exquisite natural beauty, vibrant culture and unique deity tradition that oversees an ancient way of living symbiotic with the Himalayan forest system. Manali, a world renowned tourist destination in Kullu is known for its quintessential Himalayan landscapes and adventure tourism. Kullu is also endowed with unique mountain ecology; the Great Himalayan National Park is home to vulnerable and threatened fauna and was designated UNESCO World Heritage Site status in 2014. Class hierarchies exist which define the ownership of resources and socialpolitical status of people in the society. Rajputs and Brahmins are perceived as higher castes. Rajputs dominate in land ownership and wealth. The lower classes called Harijans (scheduled castes) are mainly landless and service castes like carpenters, labourers, blacksmiths (DavidsonHunt, 1995).

Kullu arrived on the tourist map in the early twentieth century. Post 1930s, roads developed, British settlers moved in, and Kullu started becoming a popular destination among British military officers and colonial administrators. Gardner, Sinclair, Berkes and Singh (2002, p.12) advise that Kulluvians were initially reluctant to embrace the idea of the 'service industry'; people from other regions of India, like the Punjab, Lahaul and Kashmir became the main workforce in the hospitality businesses in Kullu. 'Lahaulas' (people of Lahaul) and 'outsiders', gained a major stronghold in the hotel and tourism businesses (Singh, 1989). 


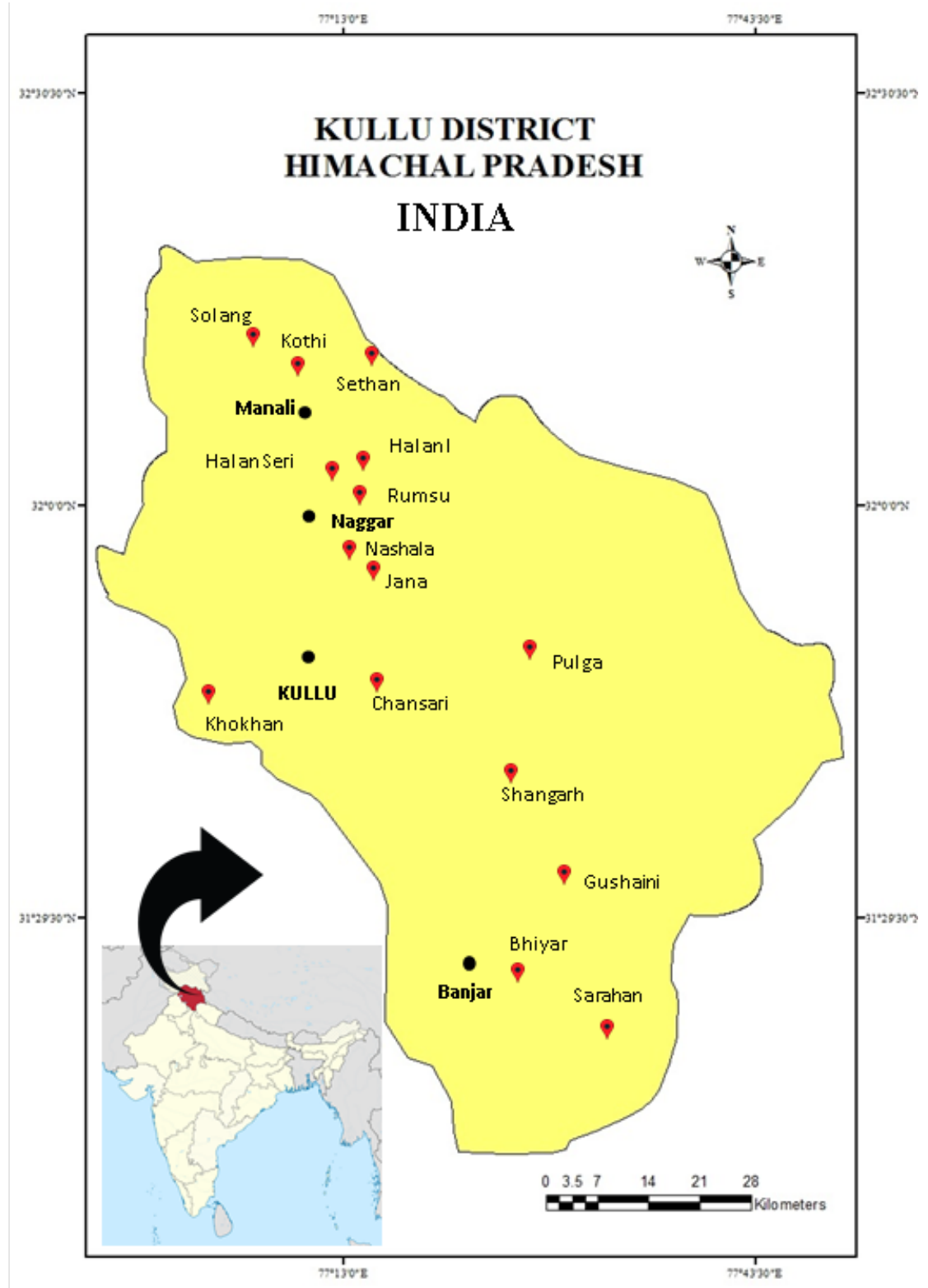

Figure 2. Map of Kullu

In spite of receiving 3.18 million domestic and 0.10 million foreign tourists in 2014 (HP Tourism website), rural communities of Kullu have not been able to achieve significant economic benefits from tourism. Most tourists who come to Manali are 'mass' tourists arriving on tours sold by travel agencies based in metropolitan cities of India. Singh (2008, p.1154) observes that the Kullu community has been alienated from tourism-related decisions and their natural resources such as springs, “are now 'owned' or 'managed' by hotel owners.” Tourism is 
mainly confined to the popular tourist hotspot of Manali, which is already grappling with the negative effects of mass tourism (Cole, 2000). The tourism employment opportunities are largely concentrated in Manali, Old Manali, Naggar, Solang Nala, Rohtang, Manikaran, and Kasol. Local people are mainly involved in operating small hotels/guest houses, cafeterias, travel agencies, selling handicrafts and organising adventure tourism activities (Singh, 1989).

Tourism development in Kullu began in the early 1990s when Kashmir, a leading Himalayan destination in India, experienced civil unrest and Kullu emerged as an alternative destination for international tourists (Gardner et al., 2002). Tourist accommodation infrastructure was largely undeveloped at that time and was unable to meet the requirements of the first wave of foreign tourists coming into Manali. Communities from villages around Manali offered beds and rooms to these early tourists (mainly backpackers) in this 'hippy era' (Hartzell, 2008, p.69), a description of the type of tourists visiting Kullu. Later, many foreign tourists started hiring cottages, secluded homes or cabins, located in orchards, which natives used only during the harvesting season. These orchard-based guesthouses (Singh, 1989) and outhouses also attracted tourists who wanted to live in privacy or practise yoga and meditation. Some backpackers preferred staying in 'village homes-cum-guesthouses' because they enjoyed the village space dominated by 'indigenous usage and not by tourism’ (Hartzell, 2008, p. 81). These early forms of homestays were rarely formally promoted because they did not appeal to the domestic tourist market, which preferred accommodation with modern amenities (Hartzell, 2008). Following the rise of tourism in Kullu post-1990s, the state Government provided incentives to develop the formal accommodation infrastructure. This prompted 'non-locals' (outsiders) i.e. from other parts of the country to invest in the hotel industry in and around Manali. The construction of guesthouses and hotels (Cole \& Sinclair, 2002) grew exponentially and has led to deforestation 
and solid waste problems (Kuniyal, Jain and Shannigrahi, 2003). Today, Kullu has a bed capacity of 21,675 (Himachal Pradesh Tourism website) in its 651 hotels/guesthouses. With an increase in commercial hotels, orchard-based guesthouses fell out of favour (Cole \& Sinclair, 2002).

Himachal Pradesh Tourism Policy (2005) recognised rural tourism as a priority area. In 2008, the state Government launched the 'Himachal Pradesh Homestay Scheme (Table 1) to: a) broaden the stakeholders' base for tourism in the State; b) take tourism to rural and interior areas of the State; c) decongest urban areas which cannot support any further tourism load; d) provide employment and economic benefits to communities in interior areas; and e) run the scheme in an ecologically sustainable manner. The scheme was adapted by the state Department of Tourism \& Civil Aviation from MoT’s (Centre Level) Incredible India Bed and Breakfast scheme (initially designed for urban India). While designing the scheme the policy makers did not consult stakeholders.

Table 1 summarises the programme's key features. It is notable that to register a rural house as a homestay it has to comply with minimum room and bathroom size and have attached (ensuite) toilet. The householder needs to stay in the premises and can claim tax exemption on income for five years and subsidies on electricity and water.

\section{Table 1}

Summary of Himachal Pradesh Homestay Scheme 2008

\footnotetext{
Key Features

- No. of Rooms that can be let (1-3)

- Room accommodation of minimum standard sizes with attached toilet facility reasonably furnished and ready for letting out to tourists/guests as prescribed under the said scheme

- State Tourism Department provides assistance in training and promotion through its
} 
website

- Inspection Committee for homestay registration approval will consist of: District Tourism Development Officer or any other officer of the Department of Tourism; Area Manager (Himachal Pradesh Tourism Development Corporation); leading hotelier/Travel Agent/Tour Operator

The major $\quad$ Bed with good quality linen; WC with lid and toilet paper; hot and cold running water; requirements parking space; well-maintained hygienic kitchen; good quality cutlery and crockery; (all not aqua guard / mineral water facility; dining area serving fresh continental/Indian mandatory) breakfast; wardrobes, chairs, working table and other necessary furniture; washing machines/dryers or laundry facility; lounge or seating arrangement; garbage disposal facilities as per municipal laws; heating and cooling arrangement in public rooms; acceptance of cash/cheque/direct debit.

Benefits Tax exemption under the Himachal Pradesh Tax on Luxuries (in Hotels and Lodging House) Act, 1979 and subsidies on electricity and water, if homestay is registered under the scheme and essentially comply with features below:

- The promoter of homestay has to physically reside there,

- Accommodation should meet mandatory minimum standard sizes (double and single bed room size is 120 Square feet and 100 Square feet respectively and 30 Square feet for bathroom / toilet).

- Accommodation should fall under a rural area.

Note: Adapted from Himachal Pradesh Homestay Scheme 2008. Retrieved October 3, 2010, from http://admis.hp.nic.in/notific/openFile.aspx?id=3391\&etype=Notice

Since the Homestay Scheme introduction in 2008, 206 homestays have registered in Kullu with the State Department of Tourism \& Civil Aviation (Table 2). Homestays in Kullu, broadly classified, are: a) registered luxury cottages, which are well marketed, and many are 
professionally managed. These attract upper middle class urban domestic tourists who expect amenities and services similar to commercial hotels. Tourists staying in these cottages rarely get to see the rural culture because homestay owners seldom stay there, contrary to the relevant legislation; and b) simple and basic rural residences, which attract budget conscious tourists and international backpackers. Here the guests stay either with the family or in orchard outhouses. Besides these, many unregistered homestays also exist in Pulga, Old Manali and Manikaran Valley but official statistics on such homestays are unavailable.

\section{Table 2}

No. of Hotels and Homestays in Kullu and their Bed Capacity

\begin{tabular}{lllll}
\hline & No. of Hotels & No. of Homestays & Bed capacity Hotel & Bed capacity Homestay \\
\hline Himachal & 2416 & 662 & 65339 & 3596 \\
Kullu & 651 & 206 & 21675 & 1183 \\
\hline
\end{tabular}

Source: Department of Tourism \& Civil Aviation, Government of Himachal Pradesh

\section{Research Methods}

An interpretivist paradigm was adopted and a qualitative research study was conducted based upon in-depth interviews and a focus group. The fieldworker, an urbanite Hindu female from HP undertook the study as part of her doctoral dissertation. She stayed in Kullu for two years and attended public meetings, gatherings, local fairs and festivals. This prolonged engagement enabled close observation of customs, livelihood practices, and social class structures. Both interviews and focus groups were conducted in Hindi; the interviews were audio recorded, analysed and later translated into English. Analysing data in the native language made it possible to maintain its richness and ensure authenticity of data. All these methods also helped to ensure criteria of trustworthiness (credibility, transferability, dependability and confirmability) as suggested by DeCrop (2004). The sampling strategy was to select fifteen villages (see Figure 2) which already have some tourist visitation but where tourists cannot stay overnight due to 
limited/ no tourist accommodation. The reason for choosing fifteen villages was to ensure broad geographical coverage of the district of Kullu. Ten participants were selected from each village through a purposive sampling method. Thick description and purposive sampling help in establishing transferability (DeCrop, 2004). Theoretical saturation tended to arise after 5-6 interviews in each village; the justification for ten interviews from each village was in terms of ensuring comparability between otherwise heterogeneous villages and enabling treatment of each equitably during analysis. During sample selection, an attempt was made to include views of a cross-section of the community i.e. people of different genders, occupations, income and in leadership positions such as heads of Panchayats (elected village administrative council) and Mahila Mandals (womens' organisations which work at grass root level in the management of resources through collective action (Davidson-Hunt, 1995)). Additionally, only houses with more than three bedrooms were selected, as very small houses would not have rooms to rent out to tourists. Six background interviews were conducted in order to clarify issues arising from the study, with the president of the Homestay Association of Kullu and the directors of prominent NGOs in Spiti and Kullu. Data collection took place in winter months, when people of Kullu are relatively free from agricultural work.

Research participation was voluntary and conversational style interviews were undertaken which generally lasted from 30 minutes to one hour. Any issues deemed sensitive or awkward were not recorded. The researcher used an 'interview guide', addressing key themes, namely, awareness, participation, socio-economic structures, and attitude towards homestays. Participants were probed about their awareness of homestays and the homestay scheme, followed by questions on the challenges they might face if they wanted to establish a homestay. Their opinion 
on the institutional agency that could help implement this scheme was also sought. Findings from previous interviews acted as building blocks for each successive interview.

According to Krueger and Casey (2015), a focus group discussion (FGD) is an effective way to gain participants' insights to evaluate and improve the existing programmes. Unlike interviews which are more personal opinions, FGDs help a group in discussing and co-creating a range of ideas. A FGD was undertaken with the presidents of ten Mahila Mandals of Kullu. The researcher contacted the Mahila Mandal Chief, Block Naggar, who invited her to join a Mahila Mandal meeting. Since each Mahila Mandal's president represents women of a village, a FGD with them could give a fair and balanced range of views of the ten villages at one place. Through the FGD extensive information was gathered on the awareness level and attitude of women of ten villages regarding homestays and the HP Homestay Scheme 2008, and the challenges that could prevent them from opening homestays. The data gathered from this FGD was compared to the interview data and it was mostly identical. This helped in verifying the accuracy of the findings. Accordingly, when theoretical saturation was achieved and no additional insights emerged (Glaser \& Strauss, 1967), one FGD was considered sufficient.

Thematic analysis of the data was guided by the procedure (Table 3) suggested by Braun and Clarke (2006). The first author conducted first, second and third stages of the analysis. In stage one, the first author undertook analysis and translations to familiarise herself with the data, and because she was well-versed in Hindi and able to construe the subtle nuances of the language. In the next two stages, the initial draft was read multiple times and was manually coded and recoded to identify underlying themes. Key issues were grouped under a common theme that captured the essence of that data. The focus of the first draft was to conceptualise and highlight the major reasons for non-participation in homestays. 
Table 3

Stages of Research and Author Roles

\begin{tabular}{lll}
\hline Stages & \multicolumn{1}{c}{ Research Work } & \multicolumn{1}{c}{ Author Role } \\
\hline Stage 1 & Familiarising yourself with Data & Author 1 \\
Stage 2 & Generating Initial Codes & Author 1 \\
Stage 3 & Searching for Themes & Author 1 \\
Stage 4 & Reviewing Themes & Author 2\&3 \\
Stage 5 & Defining and naming themes & Author 1,2\&3 \\
Stage 6 & Producing the Report & Author 1,2\&3
\end{tabular}

Note: Thematic Analysis Procedure adapted from Braun \& Clarke, 2006

In the fourth stage i.e. reviewing themes, to ensure dependability and confirmability (DeCrop, 2004), the second and third authors scrutinised the initial draft with raw themes; they worked individually on the initial themes and supporting quotes. The themes were reviewed and refined within and across transcripts for coherence, non-repetition, logic and consistency. The second and third authors identified new thematic angles overlooked or omitted by the first author. After considerable review and discussion, a few initial themes were merged or eliminated and new ones were added until consensus was finally reached. This led to stage five of the analysis when three core or overarching themes on major constraints were agreed. Further discussion went into deciding which quotes were most relevant and illustrative of a particular argument. In the final draft, quotes from interviews are preceded with name, gender and village and quotes from FGD have been preceded by the term 'FGD'. The use of pseudonyms in reporting the interview quotes instead of the participants' true names ensures anonymity. The sixth and last stage involved writing the final article that captures the essence of the raw data. Participant quotes to illustrate responses were selected in accordance with the principles of writing up qualitative research through judicious selection of statements emblematic of an issue being illustrated and often indicative of the voices of other participants who felt similarly. 


\section{Findings}

In total, 150 interviews were conducted comprising 87 males and 63 females in the age group 20-60 years. The primary occupations of participants' households (Table 4) were agriculture (117), business (23), and government jobs (10). Further, 52 of the participants indicated that there was also a tourism-related occupation (in full or in part) in their household, as follows: porters, guides, taxi drivers, photographers; and organisation of adventure tourism activities, (paragliding, skiing, rafting, zorbing, river crossing). Some of them eked out subsistence by offering ancillary services to the mainstream tourism trade by selling souvenirs and traditional Kullu dresses; renting ponies; adventure sports equipment.

\section{Table 4}

Gender \& Primary Occupation of Particpant’s Household

\begin{tabular}{|c|c|c|c|c|c|}
\hline \multirow[b]{2}{*}{ Village } & \multicolumn{2}{|c|}{ Gender } & \multicolumn{2}{|c|}{ Primary Occupation } & \multirow[b]{2}{*}{ Govt. Service } \\
\hline & Male & Female & Agriculture & Business & \\
\hline Solang & 6 & 4 & 5 & 3 & 2 \\
\hline Kothi & 5 & 5 & 6 & 3 & 1 \\
\hline Sethan & 7 & 3 & 8 & 2 & 0 \\
\hline Rumsu & 4 & 6 & 9 & 1 & 0 \\
\hline Nashala & 6 & 4 & 8 & 1 & 1 \\
\hline Jana & 6 & 4 & 7 & 2 & 1 \\
\hline Halan seri & 7 & 3 & 10 & 0 & 0 \\
\hline Halan 1 & 5 & 5 & 4 & 1 & 5 \\
\hline Chansari & 5 & 5 & 7 & 3 & 0 \\
\hline Khokhan & 6 & 4 & 8 & 2 & 0 \\
\hline Pulga & 6 & 4 & 7 & 3 & 0 \\
\hline Shangarh & 7 & 3 & 10 & 0 & 0 \\
\hline Gushaini & 6 & 4 & 9 & 1 & 0 \\
\hline Bhiyar & 4 & 6 & 10 & 0 & 0 \\
\hline Kullu Sarahan & 7 & 3 & 9 & 1 & 0 \\
\hline
\end{tabular}




\section{Reasons for Non- Participation in Homestay Scheme}

The following themes explaining non-participation in the homestay scheme in Kullu are now elaborated: socio-cultural reasons; practical reasons; and apprehensions.

\subsection{Socio-Cultural Reasons}

\subsubsection{Social beliefs and caste structures}

Every community has its personal set of values and rules and sense of shared identity. Kullu's communities follow a traditional system that believes in the rule of mythological goddesses-gods called 'devi-deotas'. Each deota (deity) controls a certain area where every member of the community is bound to abide by the deity's edicts (Berti, 2004). Improving literacy is gradually changing their way of thinking, especially among the youth; however, this way of life still defines most of the rural communal existence in Kullu. Multiple cults, myths, fairs and festivals in these villages are based on allegiance to a particular deity.

Caste based hierarchies are still prevalent in villages. People of so called 'higher' castes do not let the people from lower castes enter their houses as they believe that it might offend their deota and bring misfortune to their lives, animals and crops. Berti (2004) observes that low-caste villagers do not enter the temple and in many places women, even of high castes, do not enter the inner sanctum of a temple. In some villages like Jana and Halan I, the caste hierarchy is more rigid. Participants from these villages were more averse to homestays than others. Here, the researcher was not invited inside the house, and people preferred to talk outside.

Many participants admitted that certain social beliefs constrained them. Community members may ostracise those people who choose commercialism over traditions. 
I am from a Rajput clan (a caste perceived as higher). My family has been the main caretaker [contributes to administration and management of religious events] of the deota since ages. We are uncomfortable in letting people of low castes... stand outside our house let alone inviting them inside... Only people who are blatantly driven by money and have spare houses can allow unknown strangers to stay in their house, but the entire village would stop talking to them if the deota gets offended or a mis-happening occurs. (Khayale Ram, male, Halan 1)

Exchange of information between the members of different castes is limited. I want to start a homestay but I don't know where to go and whom to ask for guidance. The upper caste people in our village share information with the other upper class people of the village. They don’t talk to us. (Nirmala, female, Bhiyar).

Nevertheless, a few participants believe that things are changing, and the caste system is not as rigid now as it once used to be.

I know a few people in villages of Pulga and Old Manali who let foreign tourists stay in some parts of their house. Earlier, caste system was rigid in these villages as well. However, it became a secondary concern once they started seeing economic benefits that tourism brought. (Jeet Ram, male, Shangarh)

The homestay scheme has yielded some economically successful ventures and increased tourist visitation in a few villages at the periphery of Manali such as Prini, Naggar, Kanyal, Old Manali (outside our study area). This success may be due to factors like spillover of extra tourists from hotels to peripheral areas during the peak tourist season and the adjustment mechanisms of those communities. Instead of breaking the social norms, these communities have created boundaries for tourists and ensure host-guest spatial separation. 
We have no issues with foreigners coming to our house... The family lives on the upper floor and guests are not allowed in that area and in our family kitchen. There are separate kitchens for them. (Jeeva Singh, male, Solang)

Actually we have two houses. We would allow all kinds of tourists in our new house. However, we don't allow them in our ancestral house where our Deota dwells. (Saroj, female, Bhiyar)

Participants in villages like Halan, Shangarh and Jana expressed discomfort in allowing female tourists in their houses because it is taboo for women to stay inside the house when they have their monthly periods. Women must either stay outside the house or use the ground floor, which is called 'khud' (a place for sheltering sheep and cattle). Women are considered untouchable during this period and it is sacrilegious for them to touch anything belonging to the deities. However, like the caste system, the taboos related to menstruation are also not as rigid as they used to be.

\subsubsection{Daily workload of women}

Many participants, especially women, explained their inability to participate in homestay due to their busy schedule and workload. According to Census of India (2011), around half of the total cultivators and agricultural labourers and some $40 \%$ of workers in household industries are women.

Females of the household are involved in traditional female activities such as cooking daily meals, washing of clothes/utensils, childcare and household cleanliness. Apart from agriculture, women also contribute significantly to pastoralism and weaving.

During harvest time, we are so busy with work in the fields, that we don't even have time to look after our families. (Sharvani, female, Kullu Sarahan) 
Women of Kullu have to manage household duties, collect fodder for animals and work in farms. Before the onset of winter, we have to stock fuel wood from forests. (Kanaklata, female, Khokhan)

In Kullu, just like other Himalayan regions, women collect wood from forests for cooking and heating purposes, which is arduous and time-consuming work. Census of India (2011) showed that in Kullu district more than half of the households (53.17\%) depend on firewood for cooking. In rural blocks of Banjar (85\%), Sainj (74\%) and Nermand (62\%), dependence on firewood is even higher. Starting homestay operations in these areas without considering provision of alternative, renewable means of energy could put additional pressure on these women.

\subsubsection{Clash of harvest season and tourist arrival season}

With agriculture and horticulture as primary income sources, participants felt that homestay tourism might not be compatible with their existing work pattern.

When the apple harvest season begins by the end of July, everyone in the house is extremely

busy. During that time, we cannot put our energies to tourism or managing guests in a homestay. (Ratna, female, Jana)

Homestay management requires both human resources and disposable time. The process starts right from the enquiry stage leading to the reservation, the tourist arrival, stay and finally departure. The participants felt that homestays need dedicated staff to service tourist needs like preparing breakfast (sometimes other meals as well) and housekeeping. Participants also expressed apprehension about hiring staff to manage the homestay. Keeping a cook or an attendant on a seasonal basis poses problems: a) skilled workers are difficult to find; b) there is a limited pool of workers; and c) skilled workers prefer to work in larger hotels in Manali rather 
than seek seasonal employment with homestays. Further, if there is no tourist visitation, salaried staff would be an additional burden on the poor household.

\subsection{Practical Reasons}

\subsubsection{Lack of awareness/ information}

Participants from two villages, Gushaini and Pulga, have been seeing foreign tourists in their village for the last two decades. Residents of eight other villages also demonstrated significant awareness and familiarity with the concept of letting out houses to tourists because they have

many informal unregistered homestays. When probed about their awareness of the 'HP homestay Scheme 2008', four years after its introduction, 78\% of participants were unaware. They depended overwhelmingly on word of mouth or Panchayats for information about new Government schemes.

There are many schemes of the Government which Panchayat does not inform us. Due to our busy work schedule, we also don’t have time to attend the Panchayat meetings or go to enquire about the new schemes. (Ratan Singh, male, Halan-1)

Those who were aware of the scheme were not clear about how to participate.

There is a homestay in my relative's village in Goshal. We have a similar house like that homestay. However, I am not aware of the procedure for applying for this scheme... and when I asked the Pradhan (elected head of Panchayat) of our village, he too was equally ignorant about this scheme. (Rohit, male, Halan Seri)

In remote villages like Pulga, participants who already are operating guest houses and paying guest accommodations (which are family run), were also unaware of how to register on the homestay scheme. Almost all the Mahila Mandal chiefs in FGD expressed their interest in 
the scheme but said they were not aware of the process. They felt that the State Government should hold awareness sessions in villages.

\subsubsection{Lack of finance}

Monetary constraints and lack of access to micro-credit impede $\mathrm{n}$ homestay entrepreneurship. Poor people need financial support to expand/renovate their house/toilets to meet guidelines of the current scheme. The President of the HP Homestay Association observed that the main practical reason for non-participation is the lack of capital raising channels. He explained:

Many people who are interested in starting a homestay call me to enquire if some kind of financial institution exists that could provide a loan or mortgage to raise initial capital for homestay.

Many participants were sceptical of the financial viability of a homestay venture. Low levels of entrepreneurialism and risk aversion are evident. A household's perception of its prospective income from a homestay influences their scheme participation. A household already facing credit constraints shies away from investing in homestays with an unclear promise on Return on Investment (ROI). If they had surplus income, their inclination would be to invest monies in secure options like bonds that would give them better returns from a mid-term and long-term future perspective.

It would be better if I educate my children and send them to cities where they can earn money. I don’t think opening a homestay would give a good means of income. (Shivam, male, Bhiyar)

Seasonality of tourist visitation limits the earning period to summer months and is an important factor that affects their decision. Participants were also not convinced there are tourists 
who would wish to stay in their house given the attraction of other, more popular places like Manali.

People only want to go to famous places like Manali Naggar, Manikaran. I don’t think anybody would stay in our village (Paras Ram, male, Khokhan)

\subsubsection{Lack of sanitary infrastructure to comply with scheme guidelines}

The homestay scheme mandates certain minimum criteria, some of which do not fit with the realities of a Himalayan rural home. For example, the HP Homestay scheme 2008 guidelines have made it mandatory for a homestay bedroom to have an ensuite toilet facility. However, houses in rural areas of Kullu have toilets and bathrooms outside the main building as they are perceived to be 'impure' and not fit to be inside the house. There is logic behind this practice: since Himalayan homes tend to be constructed of wood flowing water may damage their structure. According to Census of India (2011), a significant proportion (41.56\%) of the households in Kullu still do not have indoor toilets and therefore would not be able to participate. In blocks of Ani (47.37\%), Nermand (46.64\%) and Sainj (45.42\%) almost half the households do not have an indoor toilet facility.

I have an old Katthkuni house and there are no ensuite toilets inside my house... I was told by the tourism officials that my house does not meet the eligibility criterion for the homestay scheme. (Lajje Ram, male, Halan Seri)

\subsubsection{Need of institutional mechanism}

Although planners who launched the homestay scheme had positive intentions, the lack of institutional mechanisms has hindered its implementation. When participants were asked about the agency best suited to help implement a homestay programme at a local level, most of them were in favour of NGOs in spite of the existence of village level organisations. The majority 
were sceptical about the ability and efficiency of both Mahila Mandals and Panchayats for homestay development because: a) these organisations are inexperienced in the hospitality and tourism domain; b) many participants affirmed, especially women, that they do not attend Panchayat meetings (Village council meetings). Hence, if Panchayats are involved in homestay development and promotion, women in the community may not be reached; c) in some villages more than one Mahila Mandal existed and due to factionalism amongst these Mandals it might not be possible to implement a plan effectively. Males in a few villages do not take seriously the Mahila Mandals.

Although our Mahila Mandal carries out a lot of developmental activities in the village but women are not independent decision-makers especially in matters of money. They would get involved only if their husbands agree... and in many cases the males think that Mahila Mandal activities are inconsequential. Males would definitely listen to NGOs. (Mahila Mandal Chief 8, FGD)

Hence involving all sections of society in homestay development could be challenging.

We have not seen the Pradhan of our village in last five years... and as far as Mahila Mandal in the village is concerned, only few old ladies are running it and they don't encourage new participation... So it is better that NGOs are involved, who can make the people aware. (Jai Singh, male, Bhiyar)

I think it is better that someone from outside the village, such as the tourism department, comes and tells people because they would be trusted more. There is a lot of friction and political conflict among various castes. (Rukmani Devi, female, Nashala) 


\subsection{Apprehensions}

\subsubsection{Lack of skills and confidence}

. Participants are not confident about their ability as potential hospitality entrepreneurs and they are unsure if they would be able to host guests from cities.

We do not have any experience to manage a tourism venture. We are people of ordinary skills. Only those people can run homestays who have some sort of experience in hotels. (Sher Singh, male, Rumsu)

Some participants expressed a lack of confidence, which inhibits their participation. Many participants felt that urban people would look down upon their basic rustic lifestyle.

We can't provide the comforts that people from the cities are used to. We have ordinary houses and simple lifestyle. They may not like it... (Lal Chand, male, Kullu Sarahan)

Our own food is very simple and basic... if a tourist, especially a foreign tourist tells me to make a particular dish which I don't know, then what will I do? They eat very different food from ours. (Beena, female, Shangarh)

Compared to formal hotels, homestays have low entry barriers in terms of investment and skills, but the participants' perceived lack of skills as a high entry barrier that may be attributed to their lack of confidence and exposure.

\subsubsection{Isolation from mainstream travel trade}

Participants feel they cannot take advantage of the opportunity presented by the homestay scheme because of a lack of networking with the travel industry. The homestay scheme has attracted significant participation from people who already dominate the formal accommodation (hotels and resorts) businesses, including regional immigrants and seasonal third party contractors. With their background in hospitality and network connections these people are better 
able to promote homestays and attract tourists; some are already leveraging online homestay booking platforms. Some participants confided that in a few villages, locals have leased out their homes to professional hotel contractors to run as a homestay. These professionals are mainly non-locals and have entered into such homestay ventures in order to benefit from the subsidised cost of electricity and water, and tax exemption (see Table 1) on the income generated from a homestay.

A homestay operator I know has contacts with travel agents in Manali and also officials of tourism department. Where would a poor person like me go to find tourists? (Prem, male, Sethan)

\subsubsection{Fear of loss of cultural values \& safety concerns}

Some participants expressed concern that, since tourists would stay in their houses, it could introduce foreign influences into their lives. Over the past few decades, they have seen the youth of Manali losing their cultural identity and imitating foreigners.

We don't like the fact that people destroy the peace of our place. Under the influence of tourists, children of Kullu are experimenting with narcotics. When a lot of money will start coming in, people would initially love it, but our culture will be destroyed forever. (Narotam Ram, male, Jana)

A few participants indicated that homestay guests could bring positive cultural influences and that tourism alone does not lead to the loss of their culture; other aspects such as exposure to satellite television may contribute to cultural erosion.

It is not necessary that tourists might cause degradation in cultural values. It is already happening... and I think the biggest contributor for it is satellite television and internet. If we want to take it in a positive stride, our children can learn so much from international guests 
staying at our home like their language, their lifestyle, their country etc. There is a foreigner who stays in our village. He grows and sells medicinal herbs and plants. He has taught this skill to many local boys as well. (Pushpa Devi, female, Nashala)

Safety-related issues of women and children in the house also concerned many participants because they have seen tourists come and stay in guesthouses for months together and engage in excessive drinking and drug abuse. Here they would be entering the house of a family, which for some is really a matter of concern.

Tourists might engage in drinking and could misbehave with the women in the house. Sometimes men are out to work and there are only women in the house. Who is going to guarantee the safety of the girls in the house? (Khayale Ram, male, Halan 1)

\section{Discussion}

This in-depth investigation into community non-participation in homestays, conducted from an insider perspective has deconstructed reasons for non-participation articulated by a host community in a developing country. The study outlined three broad constraints namely sociocultural, practical, and apprehensions (Figure 3).

Through thick description (Geertz, 1973), the study provides new insights into the significance of socio-cultural constraints. Complex socio-cultural issues such as taboos associated with menstruating women, the deity system and a rigid caste hierarchy hinder participation in homestays. Newer economic opportunities in the form of homestays have created dilemmas in the communities in the context of their traditional economic structures, household roles, socio-cultural traditions and value systems. However, homestay operators can create 'spatial separations' in the house based on their socio-cultural values and sensitise tourists about 
their lifestyles. Efforts at a grass-roots level to create cross-cultural understanding and to highlight the success stories of homestays would encourage participation and help transcend taboos and caste barriers. Once they understood their economic benefits, unregistered homestay operators in villages like Pulga and Old Manali developed adjustment mechanisms for operating homestays. They have overcome their fears of unfamiliarity of the hospitality trade, lack of skills, and caste-related issues and are now comfortable in hosting guests of any caste. Adjustment mechanisms like hosting guests in a different house or certain areas of the same house have helped them to keep their social beliefs intact, earn money, and simultaneously, avoid community ostracism. Acharya and Halpenny (2014) have noted a positive change in attitude towards the perceived lower castes in Barapaki, Nepal since they participated in homestays.

The Homestay scheme currently prescribes uniform norms (one size fits all) of infrastructure (ensuite toilets, fixed size of bedrooms/bathrooms) that are difficult for rural communities to comply with. It promotes the creation of a 'standardised' version of hospitality. Conventional accommodation industry standards form these norms and the question arises, in rural areas where a key motivator is to address poverty, whether the homestay strategy should prescribe such standards. Government assistance, informal micro-finance institutions (Ngoasong \& Kimbu, 2016), NGOs (Tosun, 2006) and networking (Steiner and Atterton, 2015) could help to solve this constraint. Lack of finance especially in rural areas constrains the development of small tourism firms (Jaafar, Rasoolimanesh \& Lonik, 2015). In the absence of micro-financing institutions, the state government should provide small loan options to encourage community participation in homestays. The banks, which already offer these kinds of loans, need to run awareness drives. 


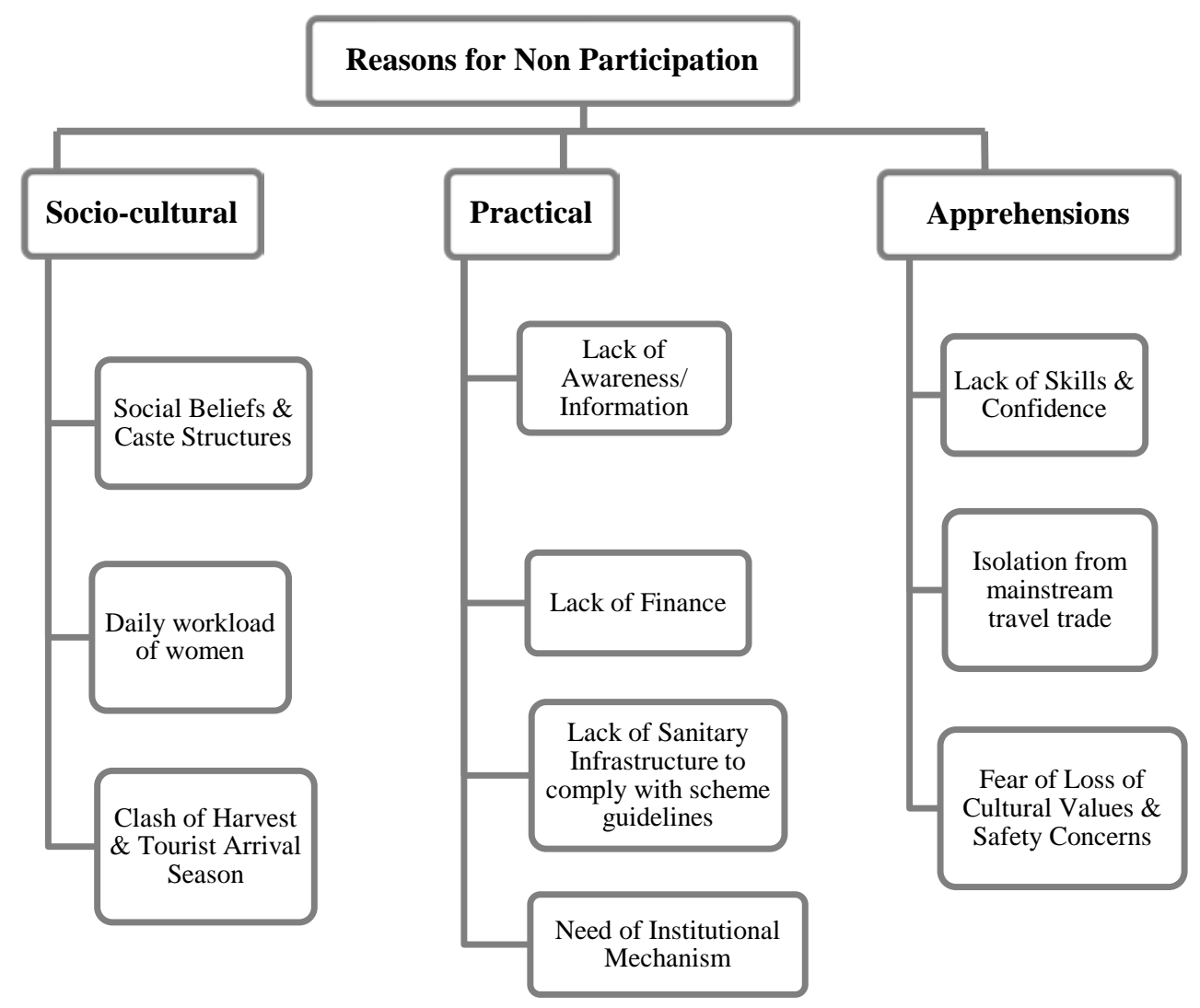

Figure 3 Reasons for non-participation in Homestays by rural Himalayan community of Kullu

The majority of homestays in Spiti (HP) are working with Spiti Ecosphere, a local NGO because these homestays have not been able to comply with scheme guidelines. Alternatively, the scheme guidelines about attached toilets should be relaxed initially or introduced in a phased manner after tourist numbers have grown. In Cambodia, Reimer and Walter (2013, p. 127) observed that although funding is provided for constructing toilets in homestays, hosts are 
encouraged to build simply and 'not change the culture of the house'. In Kayat's (2002) study, any 'clean' and peaceful household could apply to become a homestay host. They were not supposed to remodel their houses to fit into a 'standardised' hotel-like version and even with low start-up capital, anybody could participate. Similarly, Anand et al. (2012) described environmentally friendly principles adopted in homestays of Ladakh which use dry compost toilets instead of water-consuming European style toilets. These dry compost toilets are a practical solution in a region where water is a scarce resource and temperatures are often below freezing.

Another pitfall of encouraging an 'hotel-like' version of hospitality is the long-term impacts on Himalayan sustainability and culture. While the current registered homestay numbers look encouraging (Table 2), third party contractors and professional hoteliers who have ventured into homestays have mainly benefited from the scheme. In such professionally run establishments, families do not stay on the premises, and hence they fail to provide the tourists with an 'authentic' cultural homestay experience, much against the primary objective of this scheme. Homestays could become just another version of hotels, espousing similar consumption patterns and becoming a non-sustainable form of accommodation in the long term. As Scheyvens (1999) argues, 'control' of local communities over resources is critical; a similar argument holds true for locals to run homestays to ensure future Himalayan sustainability.

Participants find it difficult to register their homestays because they are unable to meet the standards set by policymakers, as also seen in homestays in Malaysia (Liu 2006; Pusiran \& Xiao, 2013), Laos (Phimmakong, 2011) and also Portugal (Kastenholz \& Sparrer, 2009) where legislation requires commercial homes to offer 'complementary activities' (swimming, tennis, horse-riding), apparently to adapt to tourists' wishes. Lynch (2003) asserts that, in their attempts 
to emulate hotel-type accommodation, small accommodations end up lacking clear product definition and deny the customer the very experience s/he came looking for. Similarly, Tucker and Lynch (2004) found that using a hotel as a benchmark for bed and breakfast accommodation grading was damaging to the intrinsic homely nature of such an accommodation product. It would be more appropriate if homestay guidelines, instead of mandating standardised hotel-like requirements focus on 'best practices' in maintaining hygiene and daily cleanliness of the premises, or focus on providing cultural experiences to the guests. Additionally, having an hotelier on the homestay inspection committee (see Table 1) for approval of homestay registration should be reviewed as it is likely to foster the prescription of hotel-like standards in awarding a registration to a homestay. Homestay development in remote mountainous areas should not be simply the province of civil servants and hospitality and tourism experts. Instead, it requires community engagement, a deep understanding of the local culture, as well as environmental expertise. Accordingly, the composition of the committee determining homestay development guidelines should be reviewed.

Current work patterns discourage much local participation as tourist peak season coincides with harvest season. The opportunity cost of tourism over farming is great, which makes homestay enterprises less appealing to the communities. Lack of time and labour constraints limit a household's decision in participating in homestays (Phimmakong, 2011). Goulding (2009, p.106) similarly observes that owners of commercial home enterprises have to 'be on call 24 hours a day' whenever guests are in residence. To overcome this challenge, future participants should be encouraged to exercise some 'control' strategies (Lynch, McIntosh, \& Tucker, 2009, p.209) such as 'house rules'. This would enable better division of time between homestay chores and farm work. Services required by guests can be catered to at fixed times without overtly 
increasing daily household chores. Educating guests as to the realities of homestay hosts' lives and engaging them constructively in being a 'good guest' might also be seen as enhancing the distinctive nature of the homestay guest experience. In Ladakh homestays, a list of dos and don’ts is on display in homestays to sensitise the guests (Anand et al., 2012).

Tourism entrepreneurship is a potential vehicle for women empowerment (Tucker, 2009) and for increasing gender equality (UNWTO, 2011). However, counter voices such as Manwa (2008) question whether tourism does in fact open doors for women. It is claimed that economic benefits are over-emphasised (Kwaramba et al., 2012) and that tourism based employment opportunities frequently reinforce stereotypical gendered divisions of labour (Harris, McIntosh, \& Lewis, 2007). This study acknowledges that women in Kullu already shoulder the majority of the workload, which leaves limited time for homestay participation. Dahles (2000) observes that homestay operations in developing countries have implications for family life, especially for women and children, because they increase a household's workload. In Reimer and Walter's (2013) study in Cambodia, gender roles are intensified as women have a double burden of cooking and cleaning, for guests and then for home. However, studies across the world have also acknowledged the crucial role women can play in a homestay and how operating a homestay brings financial independence and empowerment for the women (Acharya \& Halpenny, 2014). Therefore, one strategy would be to free up time of women in Kullu, which could then be productively used in entrepreneurial pursuits such as homestays. It is suggested that consideration be given to promotion of forms of community rather than individual management and indeed ownership of homestay operations, for example, as found in Laos (Harrison and Schipani, 2007). Here, the intention is to encourage community empowerment albeit through 
stereotypical women's work but as a stepping stone towards challenging a gender structure where menstruating women are subject to regular temporal ostracism from the family home.

The study highlights the participants' concern of not attracting any guests due to the isolated locations of their homes and villages. Lack of experience and non-familiarity with commercial hospitality practices (Pusiran \& Xiao, 2013) and lack of networks with the travel trade are key obstacles. Steiner and Atterton (2015) contend co-opetition, collaborative networking rather than competition, is a better strategy for small rural businesses to grow and overcome challenges of remoteness and resource limitations. Getz, Carlsen, and Morrison (2004) assert that due to remoteness, rural businesses are increasingly dependent on intermediaries to connect supply with demand and on destination organisations/industry partnerships for marketing efforts. While with the advent of social media and online homestay booking websites, the foregoing statement may not hold true in many places, it does so at present in the Kullu region. Many people in rural areas still do not have internet access nor use social media but a local NGO could on their behalf, undertake the promotion for now (as seen in other Himalayan regions of Ladakh). When internet usage increases in the future, locals could be trained in using it effectively for promotion. Currently, the HP Tourism Department website is the single source of promotion of these homestays. Initially, government should work with travel agencies in promoting and marketing these homestays, to help them survive the intense market competition and attract those tourists who are interested in experiencing the lifestyle and culture of people of Kullu. New itineraries and trails might also be developed connecting homestays in various villages.

An institutional mechanism to implement such tourism schemes at a local level is needed because of the inexperience of village level institutions and social divisions among factions in the village. Homestay development requires enhanced planning with greater stakeholder 
involvement and most importantly, implementation mechanisms at village level. Mere formulation of schemes is insufficient unless this challenge is addressed in the implementation of the homestay schemes.

Finally, lack of skills among rural communities is another major constraint and many participants had a poor image of their own capabilities. There is a need for: creating awareness of the scheme (Chipumuro \& Lynette, 2011); training and guidance in hospitality (Razzaq et al., 2011); and for creating an understanding of different cultures (Liu, 2006). The challenges prospective rural entrepreneurs face may be best solved through encouragement and engagement. To achieve this, a mentorship programme is proposed which would be aligned to the core vision of homestays and run through an institutional agency. Despite good intentions (just like the homestay scheme), the programme may not work as expected without equal support and involvement from communities. Tosun (2000) observes that in developing countries like India, which are divided by class, political and gender issues, NGOs help in creating awareness, training, and providing finance/marketing support. The mentorship programme would be capacity building and would promote the benefits of the scheme to the community with the focus to:

1. Communicate clearly the difference between homestays and hotels to the community in training/awareness programmes.

2. Familiarise local communities of similarities between foreign and local cultures. This would improve trust and multicultural tolerance.

3. Provide training that includes audio-visual modules and guest management role-plays so that prospective host families can learn to manage guests by dividing work and responsibility among family members. 
4. Provide basic English training in the forms of audio CDs or mp3 files for mobile phones (locally popular technology) so that prospective operators, especially women, could listen to these alongside their daily chores. This would help in improving communication skills and boost self-confidence.

5. Training participants in the use of the internet for promotion of homestays.

The mentorship programme could draw inspiration from the Accredited Social Health Activist (ASHA) programme in India. According to the National Health Mission website (http://nrhm.gov.in/communitisation/asha/about-asha.html), ASHA is a female community health worker, who acts as an interface between the community and the public health system to spread awareness on health issues and encourage/facilitate the community towards better utilisation of healthcare services. The Tourism department could run a similar initiative for promotion of tourism in rural areas through local activists, where a trained local could act as a facilitator at village level to promote homestays, create awareness and solve queries regarding homestay operations, procedures and best practices.

Moreover, the facilitator could then provide feedback on the experience of the local villagers and suggest ways to maintain, update or improve the mentorship programme. Part of the role of the facilitator would be to support the development of learning communities of homestay hosts which has been recognised as an effective way of addressing business challenges for micro firms (Kelliher \& Reinl, 2011) with the ultimate goal of moving from facilitated to independent learning. This facilitator, acting as a knowledge broker as well as network developer, should only be a trailblazer and over a period of time, the leadership needs to be grown from within each village. 
The President of the homestay association of Kullu advised that previously the State Tourism Department in association with the State owned Hotels' Department called Himachal Pradesh Tourism Development Corporation (HPTDC) delivered a training programme in basic hospitality only to registered homestay operators. However, with the proposed 'Training and Mentorship Programme', it is recommended that the state Tourism Department should focus on interested members of host community and not registered operators alone. It is recommended that Government supports and finances this mentorship programme initially and collaborates with local NGOs for its implementation.

Initially the state Government might extend the 'Hunar Se Rozgar Scheme' (which currently trains youth in tourism and hospitality) for homestays training as well. Economic Survey (201516) of HP states that a budget of 100 crore INR (£12.2 million pounds approx.) has been sanctioned for Skill Development Allowance scheme. A proportion from the scheme could be allocated to the mentorship / capacity building programme or hiring facilitators for homestay. Over time, a network of homestays should be created where each homestay owner contributes a certain percentage of revenue for financing training opportunities for future operators. Homestays in this network could also offer apprenticeships and training to new operators and enhance collaborative learning.

\section{Conclusions}

This paper set out to explore reasons for community non-participation in a homestay programme, and in so doing has contributed significantly to the existing literature. The study has listened to and given voice to non-participating members of a community in a homestay scheme and exposed rational, understandable reasons leading to decisions not to engage. Through this approach, we have been able to propose specific suggestions on how to facilitate a more 
successful community homestay programme and we have added further explanation to why plans may fail or why rural communities may hold divergent views from the planners. Below are the major theoretical and practical implications.

\subsection{Theoretical Implications}

The reasons presented for community non-participation, socio-cultural, practical and apprehensions (Figure 3), serve as an alternative community participation discourse to previous studies. Focusing upon non-participation is arguably a more action-focused approach in the sense that it helps to identify, and deepen our understanding of the nature of, those factors that affect participation of a community in homestays.

While Tosun (2000) discussed limitations of community participation in decision-making in tourism development, this study focused on reasons of community non-involvement in participation in a homestay scheme and homestay entrepreneurship. By looking at the issue from a different angle, this approach is less managerialist in perspective and enables community nonparticipants to act as a critical voice on the existing tourism development policy in question. The study has contributed to the literature on homestay development constraints, perceived by communities in a developing country context. The categorisation of major reasons i.e. sociocultural, practical and apprehensions, provided in this study may help future empirical investigations. Since homestays are a growing accommodation phenomenon, there is a need to develop new frameworks with a focus on hospitality and socio-cultural factors that affect community participation.

Reflecting upon previous typologies of community participation (Table 1), the Himachal Pradesh homestay scheme might be located on the bottom rung of the ladder i.e. coercive 
participation in Tosun's (1999) terms or non-participation as referred to by Arnstein (1969). Whilst the study here might be deemed to reflect some of the characteristics elaborated by for example Tosun such as 'top-down', 'formal' or 'paternalism', it should be recognised that the perspective of all three typologies is fundamentally from a (critical) managerial perspective. However, in our study where we have listened to the community non-participants, we suggest there is a missing rung that of 'Deliberate Non-Participation' where members of communities choose not to participate in such a scheme as the benefits are insufficiently attractive i.e. there is a failure to achieve 'coercive participation'. Whilst Arnstein (1969) identifies degrees of citizen power (Table 1) as citizen control, delegated power and partnership, 'deliberate nonparticipation' should also be recognised as a further degree. 'Deliberate non-participation' also extends Pretty’s (1995) typology.

If analysed in terms of Kayat's (2002) and Hung et al.'s (2011) frameworks, the community of Kullu does not have an enabling environment for everyone to get involved in the planning and decision-making of the homestay programme due to a top-down approach as well as rigid caste and power structures. Every household cannot comply with 'hotel-like' hospitality standards and hence misses the opportunity for participation. Community participation is also missing since the local community has low 'motivation' due to certain apprehensions, fears and prejudices. It also falls short on the 'ability' count due to non-access to information, skills and finance. Practically, non or pseudo-participation occurs and benefits those individuals who have access to more 'opportunities' through the decision-making process, information, resources and networking and existing positions of power- those individuals in the study identified as either 'elite' or 'outsiders' to the community. This study has thus helped to deepen our understanding about factors that affect motivation, ability and opportunity discussed previously. These factors are not 
mutually exclusive, for example socio-cultural factors may affect 'motivation' and 'opportunity' while practical reasons may affect 'ability' and 'opportunity.' Previous studies on homestay challenges (Kwaramba et al. 2012; Nor Ashikin \& Kayat 2010; Pusiran \& Xiao, 2013) explored mainly 'internal', 'external', 'practical' and 'apprehension' challenges but this paper has added a new dimension of 'socio-cultural' factors that also can equally affect community participation. In locating homestays within the broader umbrella of commercial home enterprises, which recognises crosscutting similarities across forms of home-related commercial accommodation, the paper has provided a stronger theoretical platform through the literature to explore and understand the phenomenon. At the heart of hospitality lie issues of inclusion and exclusion such that while hospitality must always involve inclusion, equally it always involves exclusion. In the case of Kullu, while the homestay development policy seeks to include through community participation, the guidelines concerning the homestays effectively exclude the community being targeted i.e. inhospitality is embedded in the hospitality offering.

The reality is that the scheme guidelines constructed by the State (host) have led to the boundaries of hospitality towards community participation being determined in such a way as to be inhospitable to the members of the (guest) communities concerned. This situation arises through a further significant element, which informs the determination of hospitality, i.e. the underlying ideology of who gets included and who gets excluded. We suggest it is the ideology of the accommodation industry advisers, which has led to this situation, as the current ideology is informed by traditional hotel industry norms ill-suited for homestay accommodation. Rather than employ the hotel as the benchmark model, this paper finds further evidence of the need for the private home to be the benchmark model for commercial homes such as homestays. Poor information, promotion and dissemination further compound this exclusion. In addition, 
couching the analysis in a host-guest relationship draws attention to the power dynamics in play; while the host state seeks to impose a kind of sovereignty through the design of the scheme and determining the criteria for inclusion/exclusion, we also see how the members of the guest community exercise their own agency through not engaging.

\subsection{Practical Implications}

This study has implications for policy makers as it provides an in-depth insight into the challenges the host community faces in becoming part of the homestay programme- that can help planners in creating effective solutions. It is important for them to understand the cultural adaptability of rural communities as well as the existing class, gendered and financial structures. We have suggested a number of actions to address challenges such as: spatial separation, control strategies, house rules, micro-credit provision, solutions for compliance issues with scheme, establishment of institutional mechanism. Further, we have proposed a mentorship programme to policymakers to address issues of awareness, skills, intercultural understanding and confidence to help steer greater community engagement in the scheme, with the ultimate aim of facilitating autonomous learning and community empowerment. Further, the idea of encouraging networks of homestays in the future is proposed as a mechanism to enhance collaborative learning and promotion. These networks may also help in strengthening economic resilience of these communities which will set them on the path to socio-cultural resilience. Steiner and Atterton (2015) observe that rural businesses skilfully adapt to unique site-specific challenges of rural areas and in the process play a critical role in enhancing local communities' economic, social and environmental resilience.

We recommend that planners should develop participatory mechanisms where the community is involved in decision-making processes. A homestay scheme for target 
communities should be discussed within the community initially focusing upon the three categories from this study. Identification of the community-specific issues in order to adapt the scheme accordingly would help in better participation. The scheme should not be prescriptive and be worded less rigidly to address the issue of inherent exclusions. A flexible 'plan' can create an enabling environment for entrepreneurship permitting adaptation to specific challenges of a community. This approach would encourage entrepreneurship at village level and ultimately bring in the bigger change of community inclusiveness.

This study points out the criticality of the juncture at which the homestay product is poised in the fragile Himalayan regions. In spite of the benefits that homestays offer, the challenges, real and perceptual, faced by the host community in Kullu, are significant enough to make the homestay scheme ineffective. Lack of awareness and of information about the homestay scheme has limited community engagement. Cole (2006) has highlighted the link between a community's participation in tourism and its access to information. We suggest that village level organisations, NGOs and the radio, which has a wide reach among rural areas, may be better media for spreading awareness and promoting the Homestay Scheme.

Returning to the paper's introduction, we consider Kullu district as emblematic of many remote Himalayan communities and while the findings may be limited to Kullu they may have wider international relevance to similar remote mountain destinations. The findings from this study are based upon an extended period in the field and as such this approach is unlikely to be readily transferable to other similar destinations. Further research should be conscious of the limitations of the managerial lens and give more attention to community non-participation rather than participation, being more open and reflective with regard to listening to reasons of nonparticipation. The notion of altering emphasis on participation by focusing on non-participation 
should be explored further in other destinations. In addition, we recommend more research into homestay networks and co-opetition among homestays with collaborative learning as a way to address challenges of participation in developing economies. Future studies in similar destinations could build on the themes provided in this study, or use them as indicators for empirical studies.

\section{References}

Acharya, B.P., \& Halpenny, E.A. (2014). Homestays as an alternative tourism product for sustainable community development: A case study of women-managed tourism product in rural Nepal. Tourism Planning \& Development, 10(4), 367-387.

Anand, A., Chandan, P., \& Singh, R.B. (2012). Homestays at Korzok: Supplementing rural livelihoods and supporting green tourism in the Indian Himalayas. Mountain Research and Development, 32(2), 126-136.

Andriotis, K. (2002). Scale of hospitality firms and local economic development - Evidence from Crete. Tourism Management, 23(4), 333-341.

Arnstein, R. S. (1969). A ladder of citizen participation. Journal of the American Institute of Planners, 35, 216-224.

Beliveau, A.R.A., Castagna, B.M., Cicchetti, J.M., \& Jacques, M.K. (2012). A home away from home: Launching home stay tourism in Namibia. Retrieved from E- project collection of Worcester Polytechnic Institute website: https://www.wpi.edu/Pubs/Eproject/Available/E-project-050412-195500/unrestricted/NTB_FINAL_IQP_2012.pdf

Berti, D. (2004). Of metal and cloths: The location of distinctive features in divine iconography (Indian Himalayas). In P. Granoff, \& K. Shinohara (Eds.), Images in Asian Religions: Texts and Contexts (pp. 85-113). Vancouver: UBC Press. Retrieved from daniela.berti.free.fr/IIAR_2_Chp3.pdf 
Bhalla, P., Coghlan, A., \& Bhattacharya, P. (2016). Homestays' contribution to community-based ecotourism in the Himalayan region of India. Tourism Recreation Research, 41(2), 213228.

Braun, V., \& Clarke, V. (2006). Using thematic analysis in psychology. Qualitative Research in Psychology, 3(2), 77-101.

Campbell, J. G. (2008). Sustainable mountain development: Reflections on supporting the development of inclusive and pro-environment policies in the Himalayas. In G. Rasul, \& M. Karki (Eds.), Policy Priorities for Sustainable Mountain Development. (pp. 21-30). Kathmandu, Nepal: ICIMOD.

Census of India (2011). Percentage of Households to Total Households by Amenities and Assets, Himachal Pradesh. Retrieved 13 November, 2013 from http://www.censusindia.gov.in/2011census/hlo/Houselisting-housing-PCA.html

Chalip, L., \& Costa, C.A. (2012). Clashing worldviews: Sources of disappointment in rural hospitality and tourism development. Hospitality \& Society, 2(1), 25-48.

Chipumuro, J., \& Lynette, L. (2011). The challenges of kwam emakana Community-based tourism homestay initiative In South Africa. In Proceedings of $29^{\text {th }}$ Annual EuroCHRIE Conference on Tourism \& Hospitality, Drivers of Transition (pp.152-163), Dubrovnik, Croatia.

Cole, V. (2000). Using Ecological Footprint Analysis to Measure Sustainability in a Himalayan Tourist Centre (Master's Thesis, Natural Resources Institute, University of Manitoba). Retrieved from http://www.collectionscanada.gc.ca/obj/s4/f2/dsk2/ftp01/MQ51696.pdf

Cole, S. (2006). Information and empowerment: The keys to achieving sustainable tourism. Journal of Sustainable Tourism, 14 (6), 629-644.

Cole, V., \& Sinclair, J. (2002). Measuring the Ecological Footprint of a Himalayan Tourist Centre. Mountain Research and Development, 22, 132-141. 
Dahles, H. (2000). Tourism, small enterprises and community development. In D. Hall, and G. Richards (Eds.), Tourism and Sustainable Development (pp. 154-169). London: Routledge.

Davidson-Hunt, I. J. (1995). Negotiating the Commons: Land use, property rights and pastoralists of the western Indian Himalayas (Master’s thesis, Natural Resources Institute, University of Manitoba). Retrieved from http://dlc.dlib.indiana.edu/dlc/bitstream/handle/10535/6600/NegotiatingCommons_David sonHunt.pdf?sequence=1

Decrop, A. (2004). Trustworthiness in qualitative tourism research. In J. Phillimore, \& L. Goodson (Eds.), Qualitative Research in Tourism (pp. 156-169). London: Routledge.

Economics \& Statistics Department (2016). Economic Survey of Himachal Pradesh 2015-16. Retrieved from http://admis.hp.nic.in/himachal/economics/pdfs/EconomicSurveyEng2015_16_A1b.pdf

Gardner, J., Sinclair, J., Berkes, F., \& Singh, R.B. (2002). Accelerated Tourism Development and its Impacts in Kullu-Manali, H.P., India. Tourism Recreation Research, 27(3), 9-20.

Geertz, C. (1973). Thick description: Toward an interpretive theory of culture. In C. Geertz. (Ed.), The Interpretation of Cultures: Selected Essays (pp. 3-30). New York: Basic Books.

Getz, D., Carlsen, J., \& Morrison, A. (Eds.) (2004). The Family Business in Tourism \& Hospitality. London: CABI Publishing.

Glaser, B. G., \& Strauss, A. L. (1967). The discovery of grounded theory: Strategies for qualitative research. Hawthorne, NY: Aldine.

Goulding, P.J. (2009). Perspectives of temporality in the commercial home enterprise. In P.A. Lynch, A.J. McIntosh, \& H. Tucker (Eds.), Commercial Homes in Tourism: An International Perspective (pp. 101-114). Abdingdon, UK: Routledge. 
Harris, C., McIntosh, A., \& Lewis, K. (2007). The commercial home enterprise: Labour with love. Tourism 55(4), 391-402.

Harrison, D., \& Schipani, S. (2007). Lao tourism and poverty alleviation: Community-based tourism and the private sector. Current Issues in Tourism, 10(2-3), 194-230.

Hartzell, M.A. (2008). From colonialism to neo-colonialism? Geographies of tourism in the Indian Himalaya (Master's Thesis, College of Earth and Mineral Sciences, Pennsylvania State University). Retrieved from https://etda.libraries.psu.edu/paper/8479/

Himachal Pradesh Tourism Website. http://himachaltourism.gov.in/ (Accessed 12 May, 2013).

Hung, K., Sirakaya-Turk, E., \& Ingram, L.J. (2011). Testing the efficacy of an integrative model for community participation. Journal of Travel Research, 50(3), 276-288.

Jaafar, M., Rasoolimanesh, S.M., \& Lonik, K.T. (2015). Tourism growth and entrepreneurship: Empirical analysis of development of rural highlands. Tourism Management Perspectives, 14, 17-24.

Kastenholz, E., \& Sparrer, M. (2009). Rural dimensions of the commercial home. In P.A. Lynch, A.J. McIntosh, \& H. Tucker (Eds.), Commercial Homes in Tourism: An International Perspective (pp. 138-150). Abdingdon, UK: Routledge.

Kelliher, F., \& Reinl, L. (2011). From facilitated to independent tourism learning networks: Connecting the dots. Journal of Tourism Planning and Development, 8(2), 185-198

Kontogeorgopoulos, N., Churyen, A., \& Duangsaeng, V. (2015). Homestay tourism and the commercialization of the rural home in Thailand. Asia Pacific Journal of Tourism Research, 20 (1), 29-50.

Kayat, K. (2002). Exploring the factors influencing individual participation in community-based tourism: The case of Kampung relau homestay program, Malaysia. Asia Pacific Journal of Tourism Research, 7(2), 19-27. 
Krueger, R.A., \& Casey, M.A. (2015). Focus Groups: A Practical Guide for Applied Research (5th Ed.). Thousand Oaks, CA: Sage.

Kwaramba, H.M., Lovett, J.C., Louw, L., \& Chipumuro, J. (2012). Emotional confidence levels and success of tourism development for poverty reduction: The South African Kwam eMakana home-stay project. Tourism Management, 33, 885-894.

Kuniyal, J.C., Jain A. P., \& Shannigrahi, A.S. (2003). Environmental impacts of tourism in Kullu-Manali complex in north western Himalaya, India. Part 1: The adverse impacts. International Journal of Fieldwork Studies, 1 (1), 47-66.

Lama, W.B., Jackson, R., \& Wangchuk, R. (2012). Snow leopards and Himalayan homestays: Catalysts for community-based conservation in Ladakh. In N. Chettri, U. Sherchan, S. Chaudhary, \& B. Shakya (Eds.) Mountain Biodiversity Conservation and Management: Selected examples of Good Practices and Lessons Learned from the Hindu Kush Himalayan Region (pp. 9-13). ICIMOD Working Paper 2012/2. Kathmandu: ICIMOD

Lama, W.B., \& Sattar, N. (2002). Mountain tourism and the conservation of biological and cultural diversity. Retrieved from ICIMOD website: http://lib.icimod.org/record/10888/files/411.pdf

Lynch, P.A. (2003). Conceptual relationships between hospitality and space in the homestay sector. (Unpublished Ph.D. Thesis, Queen Margaret University College, Edinburgh).

Lynch, P. (2005). Sociological impressionism in a hospitality context. Annals of Tourism Research, 32(3), 527-548.

Lynch, P.A., McIntosh, A.J., \& Tucker, H. (2009). Conclusion and research considerations. In P.A. Lynch, A.J. McIntosh, \& H. Tucker (Eds.), Commercial Homes in Tourism: An International Perspective (pp. 204-218). Abingdon, UK: Routledge.

Liu, A. (2006). Tourism in rural areas: Kedah, Malaysia. Tourism Management, 27, 878-889. 
Manwa, H. (2008). Enhancing participation of women in tourism. In G. Moscardo, (Eds.), Building Community Capacity for Tourism Development (pp. 116-122). Oxfordshire: $\mathrm{CAB}$ International.

MoT India / UNDP (2008). Redefining tourism - Experiences and insights from rural tourism projects in India. Retrieved from www.equitabletourism.org/readfull.php?AID=405

Mura, P. (2015). Perceptions of authenticity in a Malaysian homestay- A narrative analysis. Tourism Management, 51, 225-233.

Ngoasong, M. Z., \& Kimbu, A. N. (2016). Informal microfinance institutions and developmentled tourism entrepreneurship. Tourism Management, 52, 430-439.

Nepal, S.K., \& Chipeniuk, R. (2005). Mountain tourism: Toward a conceptual framework. Tourism Geographies, 7 (3), 313-333.

Nor Ashikin, M. N., \& Kayat, K. (2010). The challenges of community based Homestay programme in Malaysia. In B. Mohamed (Ed.), The state of the art and its sustainability Proceedings of Regional Conference on Tourism Research (pp. 66-73). Penang, Malaysia: University Sains Malaysia.

Nyaupane, G. P., Morais, D. B., \& Dowler, L. (2006). The role of community involvement and number/type of visitors on tourism impacts: A controlled comparison of Annapurna, Nepal and Northwest Yunnan, China. Tourism Management, 27(6), 1373-1385.

Peaty, D. (2010). Community-based tourism in the Indian Himalaya: Homestays and lodges. Journal of Ritsumeikan Social Science and Humanities, 2, 25-44. Retrieved from www.ritsumei.ac.jp/acd/re/k-rsc/hss/book/pdf/vol02_04.pdf

Phimmakong, K. (2011). Local perspective on Community Based Ecotourism: A Case Study in Ban Na in Phu Khao Khoay National Protected Area, Lao PDR (Master's thesis, Massey University). Available from http://muir.massey.ac.nz/handle/10179/2701

Pretty, J. (1995). The many interpretations of participation. Focus, 16, 4-5. 
Pusiran, A. K., \& Xiao, H. (2013). Challenges and community development: A case study of homestay in Malaysia. Asian Social Science, 9(5), 1-17.

Rasul, G., \& Kollmair, M. (2010). Sustainable Livelihood Promotion through Agricultural Development in the Hills of South Asia. In H. Fonseka (Ed.), Hill Agriculture in SAARC Countries, Constraints and Opportunities (pp. 167-182). Dhaka, Bangladesh: SAARC Agriculture Centre.

Razzaq, A.R.A., Hadi, M.Y., Mustafa, M.Z., Hamzah, A., Khalifah, Z., \& Mohamad, N. H. (2011). Local Community Participation in Homestay Program Development in Malaysia. Journal of Modern Accounting and Auditing, 7(12), 1418-1429.

Reichel, A., Lowengart, O., \& Milman, A. (2000). Rural tourism in Israel: Service quality and orientation. Tourism Management, 21(5), 451-460.

Reimer, J.K., \& Walter, P. (2013). How do you know it when you see it? Community-based ecotourism in the Cardamom Mountains of south-western Cambodia. Tourism Management, 32, 122-132.

Scheyvens, R. (1999). Ecotourism and the empowerment of local communities. Tourism Management, 20 (2), 245-249.

Sharpley, R., \& Vass, A. (2006). Tourism, farming and diversification: An attitudinal study. Tourism Management, 27, 1040-1052.

Singh, T.V. (1989). The Kullu Valley: Impact of Tourism Development in Mountain Areas. New Delhi: Himalayan Books.

Singh, S. (2008). Destination development dilemma - Case of Manali in Himachal Himalaya. Tourism Management, 29, 1152-1156.

Steiner, A. \& Atterton, J. (2015). Exploring the contribution of rural enterprises to local resilience. Journal of Rural Studies, 40, 30-45. 
Tosun, C. (1999). Towards a typology of community participation in the tourism development process. International Journal of Tourism and Hospitality, 10, 113-134.

Tosun, C. (2000). Limits to community participation in the tourism development process in developing countries. Tourism Management, 21 (6), 613-633.

Tosun, C. (2002). Host perceptions of impacts: A comparative tourism study. Annals of Tourism Research, 29(1), 231-253.

Tucker, H. (2009). The cave-homes of Göreme: Performing tourism hospitality in gendered space. In P. A. Lynch, A. J. McIntosh, \& H. Tucker (Eds.), Commercial homes in tourism: An international perspective (pp. 127-137). Abingdon, UK: Routledge.

Tucker, H. (2010). Peasant-entrepreneurs: A longitudinal ethnography. Annals of Tourism Research, 37(4), 927-946.

Tucker, H., \& Lynch, P.A. (2004). Host-Guest Dating: The Potential of improving the customer experience through host-guest psychographic matching. Journal of Quality Assurance in Hospitality and Tourism, 5(2), 11-32.

Vedwan, N. (2006). Culture, climate and the environment: Local knowledge and perception of climate change among apple growers in north western India. Journal of Ecological Anthropology, 10, 4-18. 